\title{
A VIOLÊNCIA NO CONTEXTO ESCOLAR: UMA LEITURA INTERDISCIPLINAR
}

Fábio Santos Bispo* Nádia Laguárdia de Lima“"

RESUMO: Este artigo apresenta uma abordagem interdisciplinar acerca da problemática da violência na escola. Discutem-se, primeiramente, as possíveis definições e caracterizações da violência, tomando-a a partir de diferentes dimensões, tais como a violência subjetiva, a violência simbólica e a violência objetiva, sistêmica ou estrutural. São analisadas as formas simbólicas e sociais da violência institucional que permeia o âmbito escolar, sobretudo a partir de suas relações com a noção foucaultiana de poder disciplinar. Em oposição às crescentes estratégias de controle e segregação articuladas ao biopoder que se fazem presentes no espaço escolar, destacamos a importância de uma educação que valorize a participação ativa dos jovens na construção de saídas para os impasses e conflitos presentes nas relações sociais e pedagógicas, bem como as possíveis contribuições da psicanálise para esse processo.

Palavras-chave: Violência; Escola; Poder Disciplinar; Psicanálise.

\footnotetext{
* Doutorando em Psicologia pela Universidade Federal de Minas Gerais (UFMG) e Psicólogo da Escola Judicial do Tribunal de Justiça do Estado de Minas Gerais (TJMG).

Email: fabio.siloe@gmail.com

* * Doutora em Educação pela Universidade Federal de Minas Gerais (UFMG) e Professora Adjunta do Departamento de Psicologia e do Programa de Pós-Graduação em Psicologia da Universidade Federal de Minas Gerais (UFMG).

Email: nadia.laguardia@gmail.com
} 


\section{VIOLENCE IN THE SCHOOL CONTEXT: AN INTERDISCIPLINARY READING}

ABSTRACT: This paper shows an interdisciplinary approach on the problematic of violence in schools. Firstly, we discuss their possible definitions and characterizations, considering different dimensions, such as subjective violence, symbolic violence and objective, systemic or structural violence. The symbolic and social forms of institutional violence that permeates the school are analyzed, especially for their relations with the foucauldian notion of the disciplinary power. In contrast to the increasing strategies of control and segregation articulated to biopower that are present in the school, we highlight the importance of an education that values the active participation of young people in the construction of solutions to problems and conflicts present in social and pedagogy relations, as well as the possible contributions of psychoanalysis to this process.

Keywords: Violence. School. Disciplinary power. Psychoanalysis.

\section{DEFINIC̣ÕES E CARACTERÍSTICAS DA VIOLÊNCIA NA ESCOLA}

Na contemporaneidade, o crescimento da violência no espaço escolar passou a ocupar um lugar de destaque nos discursos sociais, escolares e midiáticos, o que tem levado a um aumento de pesquisas sobre o tema. Buscam-se as suas causas mais específicas, situadas no interior das escolas, e também mais abrangentes, ou seja, suas relações com os processos sociais, políticos e econômicos. Surgiu, portanto, uma demanda crescente por investigação e compreensão do fenômeno, além da exigência de implantação de políticas e ações educacionais para o enfrentamento do problema. Cabe questionar, entretanto, o uso que se faz do termo violência e os riscos que acarretam as universalizações e generalizações precipitadas.

A palavra violência é utilizada para nomear condutas diversificadas e, em termos linguísticos, comporta múltiplas possibilidades de significação. Drawin (2011) destaca duas acepções distintas, a partir de uma raiz etimológica vinculada ao substantivo latino violentiae, que significa veemência, impetuosidade e força. Nesse primeiro sentido, a significação não estaria restrita ao universo humano, mas a força dos fenômenos físicos ou naturais tam aridades e segregação. Nesses casos, a violência juvenil, constantemente taxada de delinquência, precisa ser redimensionada e escutada em seus aspectos geradores de transformação. Para isso, entretanto, é preciso reconhecer a violência no laço social para além daquilo que 
costuma aparecer, destacando-se as nuances envolvidas nos jogos de poder das relações sociais. Žižek (2009) apresenta, nesse sentido, três formas pelas quais a violência pode manifestar-se no laço social:

1) A violência subjetiva seria a forma mais visível e designa a violência exercida por agentes sociais determinados, como indivíduos considerados malévolos, aparelhos repressivos disciplinados e turbas fanáticas, passíveis de serem identificados como sujeitos do ato cometido. Nesse caso, a agressão ao outro ou as agressões mútuas são visíveis, normalmente por envolverem o uso de uma força que excede determinados limites. Muitas das vezes, essa é a única forma de violência destacada na escola, pois é o que geralmente vira manchete, expondo as fragilidades das estruturas sociais para conter os ímpetos agressivos de seus agentes.

2) A violência simbólica, por sua vez, apresenta-se de forma mais sutil nas palavras, nomeações, classificações e formas de utilização da linguagem, não sendo, muitas vezes, reconhecida como violência, mas produzindo efeitos de forma mais insidiosa. Devido a esse caráter de invisibilidade, o agente da violência também se torna mais difuso, o que dificulta a sua superação. Se, em muitas ocasiões, a escola é o lugar onde se podem almejar transformações positivas no uso social da linguagem, justamente por ser um lugar de transmissão e crítica da língua, em outras ocasiões, a própria dinâmica escolar pode reforçar, em suas práticas disciplinares e administrativas, a proliferação desse tipo de violência.

3) A violência objetiva ou sistêmica é sustentada pelos jogos de relações sociais, políticas e econômicas, podendo ser demarcada no próprio discurso como referida à sustentação de laços de dominação e de exploração. Encontra-se geralmente arraigada nas instituições sociais e pode valer-se do poder econômico, político ou midiático para impor-se ou perpetuar-se. A violência objetiva não deixa de lançar mão de diversos mecanismos de violência simbólica e, em muitas ocasiões, até da violência física direta contra determinados sujeitos, como parte das relações de dominação.

Arendt (2000) relaciona uma forma de violência que ela designa como estrutural com a violência social. Segundo a autora, a violência estrutural apresenta-se como resultado de uma ideologia presente na sociedade, que impõe leis e regras para o controle social, privilegiando alguns grupos em detrimento de outros, determinando as desigualdades e promovendo a exclusão de determinados grupos sociais. Dessa forma, a sociedade, por ser hierarquizada cultural, econômica e socialmente, determina exclusões e discriminações 
que se reproduzem no interior das escolas, de modo que se pode interpretar a violência aí presente também como resultado da violência social (ARENDT, 2000).

Para Arendt (2000), o poder é inerente a qualquer comunidade política, pois é oriundo da capacidade humana para agir em conjunto, o que, por sua vez, requer o consenso de muitos quanto a um curso comum de ação. Nesse sentido, poder e violência seriam fenômenos opostos: a afirmação absoluta de um significa a ausência do outro. É a desintegração do poder que enseja a violência, "pois quando os comandos não são mais generalizadamente acatados, por falta do consenso e da opinião favorável, implícita ou explícita, de muitos, os meios violentos não têm utilidade" (ARENDT, 2000, p.8). Assim, é a situaçãolimite que torna possível, mas não necessária, a revolução. Para a autora, a violência destrói o poder, não o cria.

Bourdieu e Passeron (1975) também discorrem sobre a violência simbólica, relacionando-a com o exercício do poder. Para os autores, existe um poder invisível, ignorado, todavia, um poder de construção da realidade, que é o poder simbólico. Os sistemas simbólicos são estruturas sistematizadas de produção simbólica, como a língua, a arte, a religião, etc. A sua função política é a de impor ou de legitimar a dominação, assegurando a dominação de uma classe sobre a outra. O poder de violência simbólica é aquele que chega a impor significações como legítimas, dissimulando as relações de força que estão na base de sua atuação. A violência simbólica pode ser identificada na escola através da imposição de uma cultura escolar própria à classe dominante, que serve para a reprodução das estruturas de poder.

Se, por um lado, como salientam Arroyo (2007) e Arreguy, Morena-Torres e Camporez (2012), o conjunto de condutas indisciplinadas que sempre aconteceram nas escolas vem sendo interpretado e classificado como violências, a unificação de uma diversidade de condutas, bem como sua rotulação segregativa e discriminatória operam a favor da perpetuação de uma violência sistêmica que produz seus impactos nos processos de desenvolvimento humano, ético, cultural e na identidade dos sujeitos.

$\mathrm{Na}$ atualidade, um exemplo desse tipo de situação é o fenômeno denominado bulliyng. Esse termo passou a ser utilizado de forma generalista e indiscriminada, o que não contribui para a compreensão e o enfrentamento das situações específicas de violência subjetiva, na medida em que coloca em operação outras 
formas de violências mais sistêmicas. A utilização do termo de forma generalista apaga as condições específicas de cada contexto e de cada sujeito envolvido na situação.

Célio Garcia destaca, de forma veemente, a gravidade da violência presente nas práticas de nomeações e classificações. Embora sutil, trata-se de uma violência com repercussões que podem vir a ser desastrosas. Ele cita a tese de Badiou segundo a qual "o predicado 'judeu' seria uma ameaça para os próprios judeus, havendo contribuído para o extermínio durante o regime nazista" (GARCIA, 2010, p.147). O nome passa a operar com o "valor de 'significante destinal' (termo heideggeriano que sugere um tempo para além da história)" (GARCIA, 2010, p.147). Da mesma forma, outros predicados identificatórios, como 'imigrantes', 'clandestinos', 'infratores', 'repetentes', etc., podem adquirir um potencial destrutivo para os sujeitos aos quais se aplicam. As classificações desse tipo, envolvendo crianças e jovens, mostram-se cada vez mais presentes nas escolas e na sociedade, podendo ocorrer tanto por parâmetros morais quanto baseadas no rendimento escolar. Podem ocasionar efeitos nefastos para os sujeitos, pois geram discriminações e exclusão social, fixando-os a um destino trágico, já que eles passam a ser considerados 'fracassados' ou até 'perigosos' socialmente e, por isso mesmo, alvos de uma violência repressora.

A violência nas escolas não é um fenômeno recente nem exclusivo de nosso país, mas apenas recentemente ela passou a ser fonte de preocupação e interesse social, levando a um incremento de pesquisas sobre o tema. Na Europa, o tema começou a ser estudado nos países escandinavos na década de 1970, atingindo outros países como a Inglaterra, a Holanda e a Espanha na década de 1980 e promovendo uma maior compreensão das diversas facetas que envolvem a violência (SPOSITO, 1998). No Brasil, esse tema ganha espaço nas discussões e pesquisas acadêmicas na década de 1980, quando a violência no contexto escolar é analisada como resultado do processo de democratização das escolas.

Em concordância com Goldenberg (2011), consideramos que a violência é um processo com uma lógica própria, pela qual todos nós temos alguma responsabilidade. Não se trata de uma lógica restrita ao sujeito, nem ao seu núcleo familiar. Há uma ordem simbólica que cria as condições a partir das quais cada um, a seu modo, a subjetiva. Goldenberg (2011) retoma Girard (1983), em La violência y lo sagrado, para lembrar que não há violência sem espetáculo, e que essa colocação em cena supõe um efeito 
contagioso do qual devemos nos precaver. O autor conclui que a violência não pode ser separada de sua representação e de sua subjetivação. Ele nos adverte de que a diversidade e a complexidade das manifestações, etiologias e formas de abordagem da violência a fazem resistente a indicadores quantitativos precisos e simples.

O debate atual sobre o bulliyng introduz uma série de questionamentos sobre a utilização do termo, o seu alcance e o que ele apresenta de novo. Segundo Goldenberg, o crescimento desse fenômeno em todo o mundo está relacionado a três fatores principais. Uma primeira transformação social que substitui o conceito de autoridade como vetor social e relacional pelo de segurança como metavalor. A violência se situa, assim, como resposta a um declínio social do mestre, que leva a uma lógica da rede com sua horizontalidade. Nessa perspectiva, há uma vitimização horizontal. Ou o sujeito se coloca como vítima ou como provocador e como espectador mudo. Uma segunda transformação está relacionada ao lugar ocupado pelos objetos de consumo na atualidade, os gadgets modernos. $\mathrm{O}$ intercâmbio crescente entre os próprios jovens, e através dos suportes digitais, de imagens e textos de agressão, junto à proliferação dos reality shows televisivos, em que se expõem os atos violentos, confirmam que a violência, hoje, inclui a cena mesma e a fascinação que produz entre os atores e espectadores. E, finalmente, a crise das identidades sexuais, que leva à dificuldade de encontrar uma referência para a masculinidade e a feminilidade. Assim, há um aumento dos estilos viris entre as mulheres, com o aumento das condutas agressivas por parte das jovens (GOLDENBERG, 2011, p.34).

Goldenberg (2011) lembra ainda a homogeneização dos estilos de vida, que leva à preferência por signos normativos, reforçam um imaginário de igualdade que leva à segregação daqueles que, por uma razão ou outra, se apresentam como diferentes ou deficitários (gordos, sem roupas de marca, imigrantes, homossexuais...). Estes que encarnam a diferença estranha provocam o ódio do grupo. Como destaca o autor, o bullying envolve sempre um ternário, formado pelo(s) agressor(es), pela(s) vítima(s) e pelo grupo de espectadores, muitas vezes, mudos.

Se a utilização do termo bulliyng pode levar ao apagamento das singularidades, como um efeito de toda classificação, ela permite, entretanto, a entrada do discurso jurídico em cena, que introduz a discussão sobre a responsabilidade das escolas nas situações de violência que ocorrem no interior dos seus espaços, pois, como vimos, a violência objetiva é aquela que ocorre nas instituições sociais, dentre elas, a escola. 
Algumas pesquisas realizadas em serviços de saúde atestam que grande parte das crianças encaminhadas para esses serviços provém de instituições escolares com queixas de comportamentos violentos. Segundo Souza (2002), a maior parte dos encaminhamentos de crianças feitos pelas escolas para os serviços de saúde tem como causa os problemas de aprendizagem e de comportamento. A maior parte das queixas por problemas de comportamento relacionados à escola é por agressividade/nervosismo (35,5\%) e dificuldade de socialização $(17,8 \%)$. Esse aumento considerável de encaminhamentos de crianças para os serviços de saúde com queixas de comportamentos violentos e/ou agressivos aponta para a necessidade de se considerar a relação desse fenômeno com a instituição escolar.

Para o trabalho da psicologia e da psicanálise na escola, é importante esclarecer esses modos de violência mais implícitos nos laços sociais, porque há sempre o risco de que o saber técnico seja tomado como instrumento a favor da manutenção de alguns tipos de violência. Essa violência que Žižek (2009) chama de objetiva ou sistêmica e que é nomeada por Arendt (2000) como estrutural lança mão de diversas estratégias simbólicas, dentre elas, do próprio poder epistemológico, ou seja, dos instrumentos que o saber proporciona, a favor do controle dos sujeitos. Michel Foucault (1994) esclarece, de forma mais pormenorizada, essa violência institucionalizada nos métodos disciplinares, presentes nas práticas discursivas e que, grande parte das vezes, é utilizada para combater a violência subjetiva mais direta, mas sem que haja uma percepção de outras dimensões que a sustentam e põem em jogo.

\section{A VIOLÊNCIA INSTITUCIONALIZADA NO LAC̣O SOCIAL}

Freud (1930/1996), ao refletir sobre a existência de um mal-estar na cultura, defende a impossibilidade de se eliminar por completo as dificuldades e os conflitos presentes nos relacionamentos humanos. Ele propõe, como lembram Arreguy, Morena-Torres e Camporez (2012), que a forma mais penosa de sofrimento humano advém de seus relacionamentos com os outros, sobretudo os mais íntimos e próximos, que se constituem a partir dos processos de identificação, determinantes da subjetividade. Freud defende que não existe uma solução universal para aplacar o mal-estar presente nas interações sociais. Se a educação é necessária para a formação humana, persiste uma dimensão ineducável em todo sujeito, que 
aponta para o real pulsional. As tentativas de erradicação dessa dimensão ineducável acabam por promover sua irrupção de forma drástica e, por vezes, destrutiva.

Destacamos, nesse sentido, a dupla função da ordem simbólica em relação à violência. Por um lado, funciona como o elemento de mediação transcendente graças ao qual os confrontos imaginários entre os semelhantes podem encontrar soluções pacificadoras. Por outro, extrai sua força de uma violência que pode inclusive vir a ser mais letal que a própria violência a que ela visa conter. De um lado, pois, há uma função pacificadora e estabilizadora na cultura e nos seus mecanismos simbólicos de educação das pulsões e, de outro, há uma função violenta que visa justamente a constranger os indivíduos a adequarem-se às normas.

Benjamin (1986) já identificava esse elemento violento presente nos dispositivos simbólicos. Ao analisar o poder que sustenta e fundamenta a esfera do direito, ele propõe que um elemento ameaçador pertence à sua ordem de maneira irrevogável, "pois o poder mantenedor do direito é um poder ameaçador" (BENJAMIN, 1986, p.165). Há, dessa forma, uma violência que se institucionaliza e se organiza em dispositivos simbólicos, como na própria lei e nos aparelhos repressivos do Estado. Essa violência permanece velada, mas se coloca como necessária para manter o funcionamento da ordem cultural, de modo a ser socialmente legitimada. Surge, assim, um aparato simbólico coercitivo que servirá para inibir as desordens. O resultado é que temos, de um lado, uma violência supostamente legítima, não apenas apoiada nas instituições sociais, mas por elas exercida; e, de outro, uma violência ilegítima, praticada por aqueles que resistem à ordem, colocando-se como uma ameaça ao poder vigente.

No interior da escola, aqueles alunos considerados perigosos passam, pois, a ser alvos dos dispositivos institucionais de controle. Os meios utilizados por esses dispositivos, com sua violência considerada legítima, precisam recorrer a técnicas diversas, signos de autoridade e a demonstrações de força para ratificarem sua legitimidade. Freud esclarece que, apesar de todos os benefícios que a vida social traz para os homens, os sacrifícios que ela exige para tornar possível a vida comunitária podem ser sentidos como um pesado fardo. Desse modo, a civilização "tem de ser defendida contra o indivíduo, e seus regulamentos, instituições e ordens dirigem-se a essa tarefa" (FREUD, 1927/1996, p.16). Ao mesmo tempo, pois, em que a ordem simbólica protege o sujeito do desamparo, imprime também sanções que podem abater-se violentamente sobre os indivíduos recalcitrantes. 
São essas técnicas de controle e sanção que Foucault esclarece ao tratar do biopoder como um poder centrado na administração dos corpos e na gestão calculista da vida (FOUCAULT, 1999). O biopoder ajuda a legitimar a violência social justamente por deslocar sua força da ameaça de morte contra o indivíduo em direção ao controle de sua vida. É o que Foucault esclarece na seguinte passagem:

\begin{abstract}
A lei não pode deixar de ser armada e sua arma por excelência é a morte; aos que a transgridem, ela responde, pelo menos como último recurso, com essa ameaça absoluta. A lei sempre se refere ao gládio. Mas um poder que tem a tarefa de se encarregar da vida terá necessidade de mecanismos contínuos, reguladores e corretivos. Já não se trata de pôr a morte em ação no campo da soberania, mas de distribuir os vivos em um domínio de valor e utilidade. Um poder dessa natureza tem de qualificar, medir, avaliar, hierarquizar, mais do que se manifestar em seu fausto mortífero; não tem que traçar a linha que separa os súditos obedientes dos inimigos do soberano, opera distribuições em torno da norma. Não quero dizer que a lei se apague ou que as instituições de justiça tendam a desaparecer; mas que a lei funciona cada vez mais num contínuo de aparelhos (médicos, administrativos, etc.) cujas funções são, sobretudo, reguladoras. Uma sociedade normalizadora é o efeito histórico de uma tecnologia de poder centrada na vida (FOUCAULT, 1999, p.135.)
\end{abstract}

A sociedade funciona, nesse sentido, sob a égide do biopoder, que assegura a constituição de uma sociedade normalizadora, cujos mecanismos de regulação e correção produzem, avaliam e classificam as 'anomalias sociais'. ${ }^{1}$ Nessa sociedade, os indivíduos são tomados como objetos de medidas reguladoras e corretivas, submetidos à quantificação generalizada dos comportamentos e dos desvios, classificados como normais ou patológicos (LIMA; REZENDE, 2013). O discurso científico defende o controle sobre os corpos, a vida e a morte, reforçando o biopoder. Se, em algumas situações, como para os jovens envolvidos com tráfico de drogas e moradores de favelas, a ameaça de serem mortos pela polícia ainda deixa transparecer essa força mortífera da lei, é preciso chamar a atenção para esse outro tipo de violência, articulado à norma e ao biopoder, que permanece velado nos dispositivos de controle dos corpos e que, justamente por esse velamento, pode causar tantos estragos na vida dos sujeitos. Daí a importância de se indagar como as técnicas disciplinares na escola podem ser empreendidas como técnicas relativas ao biopoder. 


\section{A DISCIPLINA INSTITUCIONAL E SUA RELAÇÃO COM A VIOLÊNCIA NA ESCOLA}

Segundo Foucault (1994), as técnicas disciplinares e o exame surgiram no século XVIII com o objetivo de transformar os homens em força de trabalho produtiva, proporcionando-lhes o sentimento de utilidade máxima e diminuindo sua capacidade de revolta e de resistência contra o poder instituído. O que ele chama de poder disciplinar tem o objetivo de tornar os homens dóceis politicamente, por intermédio, principalmente, das estratégias de organização do espaço e de controle do tempo. A vigilância é, nesse sentido, um dos principais instrumentos de controle, devendo ser contínua, discreta e, ao mesmo tempo, vista por todos.

Foucault (1994) nomeia como 'disciplinas' os métodos que permitem o controle minucioso das operações e atividades do corpo. Elas visam a potencializar as energias e aprimorar as aptidões, adestrando os indivíduos, tornando-os dóceis e produtivos. Assim, o conjunto das estratégias de controle social que incidem sobre o corpo das pessoas configura o poder disciplinar, que inclui recursos coercitivos como vigilância, sanções e exames.

O poder disciplinar pode ser relacionado com a disciplina escolar. A disciplina distribui os indivíduos no espaço, permitindo o controle da localização e da circulação dos alunos, bem como das atividades que realizam. A determinação de lugares, a organização das carteiras em fila, bem como a compartimentalização do ambiente são estratégias que permitem vigiar, romper as comunicações perigosas, além de criar um espaço onde o trabalho de cada um possa ser mais bem conhecido, controlado e utilizado. A organização do espaço determina uma hierarquia entre as pessoas e entre os objetos, a partir da constituição do que Foucault chama de quadros vivos "que transformam as multidões confusas, inúteis ou perigosas em multiplicidades organizadas" (FOUCAULT, 1994, p.172). É, desse ponto de vista, uma importante técnica de poder utilizada pela escola, pois permite, por um lado, conhecer o potencial de cada um, classificando-os em séries ou por desempenho acadêmico, e, por outro, manter sob controle toda uma multidão de estudantes, cujos esforços devem ser cuidadosamente direcionados para a melhoria do desempenho.

O horário determinado de trabalho produz um condicionamento que também serve ao controle das atividades dos indivíduos. A disciplina requer esforço do indivíduo para incorporar procedimentos precisos e padronizados, cuja função é 
aumentar a eficiência. A eficiência da disciplina reside em obter o melhor resultado com o menor desgaste possível, sem repressão ou o uso de uma força violenta, mas com a utilização de instrumentos manipulados para que o corpo seja utilizado da forma mais adequada. A duração de uma aula, por exemplo, bem como os diversos recursos audiovisuais, são determinados de modo a aproveitar o máximo da capacidade de atenção cognitiva e a evitar um desgaste que coloque em risco o desempenho acadêmico.

Os exercícios também se constituem como mecanismos utilizados para garantir a formação evolutiva de indivíduos diferenciados e para um aprimoramento contínuo da performance dos alunos. Trata-se, como mostra Foucault, de "prescrever a cada um, de acordo com seu nível, sua antiguidade, seu posto, os exercícios que lhe convêm" (FOUCAULT, 1994, p.182). Essa prática, inspirada nas instituições militares e religiosas, passou a ser assimilada pelos programas educacionais, de modo que os próprios exercícios têm um papel diferenciador e definidor de níveis e categorias.

Apesar da tentativa de controle operada pela escola, alguns alunos elaboram estratégias de resistência aos mecanismos disciplinares vigentes no sistema escolar, encontrando saídas alternativas, cumplicidades subversivas ou paralelas à hierarquia burocrática. Tentam escapar à vigilância, desafiam os mecanismos de punição e burlam as normas estabelecidas. Mas, como ressalta Foucault, essas estratégias e práticas alternativas sempre têm um caráter paradoxal, pois articulam elementos opostos que se sustentam mutuamente.

Essas práticas alternativas e transgressoras revelam a origem da vitalidade que, conflitante com a disciplina escolar, traz um potencial transformador raramente enfatizado. Assim, no âmbito da escola, as práticas de transgressão revelam seu potencial transformador, constituindo as bases para processos educativos democráticos que superem as relações de saber-poder disciplinar, na medida em que forem assumidas coletiva (consolidando relações de reciprocidade e solidariedade) e ativamente (cultivando a diversidade de iniciativas e interações). E, para potencializar a rede viva de solidariedade, criatividade, liberdade e organização cultivada no cotidiano escolar, é preciso desvencilhá-la do caráter de transgressão e delinquência que lhe é impingido pelo sistema disciplinar de vigilância e sanção.

Existe, portanto, uma importante relação entre violência e disciplina. A constituição dos alunos 'violentos' na escola pode ser pensada como pertinente à manutenção da ordem disciplinar. Isso pode ser compreendido da seguinte forma: a escola segrega e 
exclui sistematicamente todo aquele que manifesta comportamento divergente, submetendo-o a vigilância constante e a punições exemplares, e, sobretudo, impede o surgimento de formas amplas e manifestas de rebeldia.

Como adverte Fleuri (2008), a manutenção, sob o controle penal, de um meio transgressor no âmbito da escola torna-se um antídoto ao desenvolvimento de processos democráticos. A construção de processos participativos, dialógicos, críticos e cooperativos implica, pois, a desconstrução dos dispositivos disciplinares de poder.

Ubjeto (2011) destaca a diferença entre a violência fruto da desregulação social, de outra violência, mais ligada aos sentimentos de fracasso e humilhação dos segregados. Seriam, pois, duas formas de mal-estar, coletivo e subjetivo. O autor considera que a distinção entre elas se faz importante para avaliar as respostas dos sujeitos. No primeiro caso, a violência se dá como forma de restaurar algo do lugar de exceção, anulado pelo empuxo à uniformização e exclusão do sujeito, coisificado e reduzido à condição de consumidor e consumível. No segundo caso, a violência se dá contra o laço social, para destruir o sistema, pondo em cena a violência como signo da pulsão de morte. Aqui o acontecimento se mostra fora de medida, com um sentimento ligado ao pulsional.

De acordo com a psicanálise, as medidas de contenção e erradicação do mal-estar acabam por exacerbar a agitação, a falta de concentração e a violência nas escolas. Quanto mais se pretende homogeneizar as formas de vida, mais se segrega (TIZIO, 2005). Oque é segregadonão desaparece, mas se transforma em um obstáculo, que insiste, fazendo naufragar o discurso. Ou, parafraseando Lacan (1955-1956/1988), aqueles impulsos que são rejeitados no simbólico - cuja manifestação é suprimida ou silenciada no âmbito da palavra — retornam no real, por meio de atos destrutivos.

\section{PERSPECTIVAS PARA SE LIDAR COM A VIOLÊNCIA NAS ESCOLAS}

Para que a instituição escolar não seja tão somente uma instituição disciplinar, mas também um espaço de criação e transformação social, comprometida com a formação de cidadãos críticos e reflexivos, ela precisa propiciar a articulação entre diferentes contextos, subjetivos, sociais e culturais. Para Freire (1975), trata-se de compreender e construir processos educativos em que diferentes sujeitos, de forma autônoma, elaborem uma consciência crítica 
na relação de reciprocidade (cooperativa e conflitual) com outros sujeitos, criando, sustentando e modificando contextos significativos que interajam dinamicamente com outros contextos.

Tal concepção de educação traz a necessidade de reelaborar a concepção de educador. O processo educativo consiste na criação e no desenvolvimento de contextos educativos e não simplesmente na transmissão e assimilação disciplinar de informações especializadas. Educador, nesse sentido, é propriamente um sujeito que se insere num processo educativo e interage com outros sujeitos, dedicando particular atenção às relações e aos contextos que vão se criando, de modo que contribua para a explicitação e a elaboração dos sentidos (percepção, significado e direção) que os sujeitos em relação constroem e reconstroem. Nesses contextos, Freire (1974) defende que o currículo e a programação didática, mais do que um caráter lógico, terão uma função ecológica. Sua tarefa não será meramente configurar um referencial teórico para o repasse hierárquico e progressivo de informações. Sua competência será prever e preparar recursos capazes de ativar a elaboração e a circulação de informações entre sujeitos, de modo que se auto-organizem em relação de reciprocidade entre si e entre seus respectivos ambientes.

O processo educativo constitui-se, assim, simultaneamente, na perspectiva dos sujeitos singulares, como relação entre pessoas mediatizadas pelo mundo, como afirma Freire (1974). Ao mesmo tempo, na dimensão contextual, configuram-se relações entre mundos (culturais, sociais, ambientais) que se transformam - ou se educam - reciprocamente, na medida em que são mediatizados pelas pessoas que interagem dialogicamente.

Todas as contradições, conflitos de interesse, relações de poder, discriminações, exclusões e formas de violência presentes na sociedade estão presentes também no interior das escolas. Os problemas sociais invadem as salas de aula, interferindo nos processos de aprendizagem escolar. Assim, a escola é uma instituição que utiliza o poder disciplinar para o controle social. No entanto, ao mesmo tempo em que ela produz corpos dóceis e submissos, ela também produz comportamentos de transgressão, como forma de não submissão às regras impostas. Para Freire (1974), à medida que a transgressão é rotulada como 'violência' e passa a ser submetida à clandestinidade, ela deixa de operar como potencial criador e torna-se destrutiva, realimentando o sistema de controle.

Segundo Arantes (2013), a violência, na atualidade, é fruto de um longo e complexo processo histórico que, de forma contínua 
e intensa, tem condenado parte da população brasileira ao descaso e à subcidadania, privando-os de mecanismos de proteção social. A autora comenta, em concordância com Hébrard, que um dos fatores que está na raiz da violência encontrada nas médias e grandes cidades brasileiras é a separação das crianças em dois mundos que não se encontram, como a escola pública e a escola privada. Essa separação acaba certamente em um desastre, pois a escola, como lugar onde se partilha uma cultura comum, é absolutamente essencial numa democracia. Hébrard comenta, segundo a autora, que a sociedade brasileira estaria diante de uma escolha: educação ou tanques nas ruas.

Arroyo (2007) considera que a instituição escolar não dialoga com a sociedade, isolando-se e evitando o debate público sobre os problemas que acontecem em seu interior. Apesar dos avanços no equacionamento da relação educação-sociedade, Arroyo considera que ainda permanece uma cultura de isolamento das instituições escolares. Ele levanta a hipótese de que talvez a escola tenha reduzido sua função a ensinar, a transmitir conteúdos, habilidades e competências para a inserção no mercado, estando mais sensível às exigências do mercado do que aos grandes embates da sociedade. Assim, o autor observa que, diante da pressão para que as escolas se tornem mais públicas, um caminho para essa abertura ao público é a sua constituição como um espaço de embate dos problemas que afetam toda a sociedade. É próprio dos espaços públicos abrirem-se aos debates públicos, publicizando conhecimentos e análises, valores, sentimentos e políticas que afetam o coletivo. Dessa forma, cabe à escola se abrir para o debate público, revelando as dificuldades e tentativas de compreensão e enfrentamento da situação, para que a violência escolar possa deixar de ser vista como um fenômeno isolado e circunscrito à escola e possa ser analisado na sua complexidade e abrangência, como um fenômeno que não é só escolar, mas social, buscando soluções coletivas, levando à criação de políticas públicas para a solução do problema.

Para além das relações existentes entre as escolas e os contextos sociais, políticos e econômicos nos quais elas estão inseridas, a psicanálise nos ensina a reconhecer os sujeitos envolvidos nas situações de conflito em suas singularidades. Qualquer trabalho voltado para os jovens em situação de violência deve considerar a articulação possível entre o universal e o singular. Para tanto, ao invés de estratégias pautadas em modelos universais, deve-se elaborar projetos de intervenção que incluam as especificidades. 
Uma possibilidade de se atuar nas escolas é através da oferta de espaços para a palavra aos sujeitos envolvidos em situações de violência escolar. Um trabalho realizado em uma escola pública de ensino fundamental tem permitido aos professores uma postura ativa na elaboração de soluções contingentes para lidar com alguns impasses surgidos na relação pedagógica. Utiliza-se, para esse fim, o dispositivo da conversação orientado pela psicanálise, que é assim definido por Miller: "Uma conversação é uma série de associações livres. A associação livre pode ser coletivizada na medida em que não somos donos dos significantes. Um significante chama outro significante, não sendo tão importante quem o produz em um momento dado" (MILLER, 2003, p.16). A proposta de ofertar um espaço para a palavra aos professores surgiu a partir da queixa formulada por eles com relação aos alunos. Referenciados pela psicanálise, buscamos a implicação dos professores nas situações de conflito em que estão envolvidos. Trata-se de abrir possibilidades para que eles reflitam sobre os efeitos de seus atos e palavras sobre os alunos. As nomeações dos alunos-problema pelos professores, como "violentos", "agressivos" ou "hiperativos", por exemplo, fazem perpetuar a violência simbólica nas escolas e têm efeitos segregativos sobre os jovens, agravando as situações de conflito. Nas conversações com os professores, é ofertado, a cada sujeito, um lugar em que ele poderá ter a possibilidade de entrar num discurso, em uma tomada de enunciação (LACADĖE, 2000). Nesse espaço coletivo de conversação, são valorizadas as opiniões divergentes, que exprimem as diferentes leituras e percepções de uma mesma situação. A conversação propõe o surgimento de uma fala própria de cada sujeito (VASCONCELOS; SANTOS; SANTIAGO, 2009). Assim, os professores percebem que experimentam, interpretam e reagem às situações de forma particular. Busca-se extrair, por meio das conversações, a dimensão subjetiva.

Numa das conversações realizadas com os professores sobre a possível perda da autoridade na época atual, cada professor teve a chance de definir o que é autoridade para ele, descrevendo os comportamentos dos alunos que o incomodavam. A partir de um tema proposto pelos professores, "a perda da autoridade", cada sujeito pôde nomear a sua dificuldade de forma particular. Uma professora declarou no grupo que não sabia lidar com as manifestações de "sexualidade exacerbada" dos alunos. O problema, antes centrado "no aluno", sofreu um deslocamento, na medida em que a professora reconheceu a sua dificuldade em lidar com a situação. As conversações promovem uma implicação dos sujeitos nas situações das quais se 
queixam, o que lhes permite refletir sobre a responsabilidade de cada um nos conflitos existentes no espaço escolar e buscar soluções coletivas. A partir dessa tomada de posição dos professores, é possível criar estratégias para a melhoria do vínculo educativo. Busca-se extrair, a partir da troca entre os componentes do grupo nas conversações, um saber que favoreça a relação professor-aluno e a transmissão pedagógica. Tendo em vista a complexidade que envolve as situações de violência escolar, faz-se necessário buscar soluções que não sejam pautadas em modelos repressivos e segregativos, mas voltadas para o fortalecimento dos vínculos educativos.

França Neto e Randow (2012) advertem que não é apenas pelas tentativas de contenção do gozo irregular dos adolescentes que uma perspectiva tanto clínica quanto política de trabalho pode ser construída. "Não é a partir de um enredamento ou classificação do ato infracional que cometeram, inserindo-o nas normas da sociedade, que um sujeito pode advir, mas de um lançar-se $a$, onde a busca de si construa-se, em processo, no próprio lançamento" (FRANÇA NETO; RANDOW, 2012, p.11).

Célio Garcia relaciona essa ideia de lançamento à construção de um "pro-jeto" conjunto, ao discorrer sobre alguns princípios diretivos para intervenções junto a jovens infratores ou em conflito com a lei. "Um pro-jeto", diz o autor, "não se reduz à inserção, ou à inclusão na sociedade de consumo" (GARCIA, 2011a, p.185). De igual modo, não se trata, no âmbito da escola, apenas de buscar a inclusão dos alunosproblema às suas normas de conduta. A frase de um garoto numa conversação, escolhida como tema para a Jornada Internacional do Centro Interdisciplinar de Estudos sobre a Criança (CIEN) de 2013, aponta bem a recusa aos projetos estabelecidos unilateralmente: "Me inclua fora dessa" (BARROS-BRISSET, 2013, p.7). Essa lógica da inclusão/exclusão precisa ser repensada se almejamos encontrar soluções para superar a violência na escola. Não se trata de incluir os alunos numa ordem que eles infringem, afinal, são justamente os furos da norma os pontos a partir dos quais o sujeito se produz para além da dominação. É no espaço desse furo (ou desse lapso) que pode haver transformação da lógica de controle e dominação, se esse espaço puder ser apropriado pelos próprios atores sociais (alunos e professores) para a invenção de saídas próprias para os impasses vivenciados no cotidiano.

É preciso evitar os equívocos que colocariam o trabalho do psicólogo a serviço da biopolítica. Podemos evocar Giorgio Agamben (2010), que nos apresenta uma problematização foucaultiana 
relacionada com a que foi aqui discutida. Ele destaca que o corpo biológico do cidadão ocupa posição central nos cálculos e estratégias do poder estatal. Isso significa que a política moderna transformouse numa biopolítica, em que a vida politicamente qualificada (bios) perde todo seu espaço para a vida nua (zoê - a vida natural, que coincide com o corpo biológico dos cidadãos, despojado de toda relevância política. Uma possível contribuição psicanalítica preconiza justamente a abertura de espaço para a emergência do sujeito, para além de seu corpo biológico. Ou seja, quando o cálculo utilitário e a biopolítica excluem totalmente da cena as dimensões incalculáveis, contingentes e sutis que concernem ao sujeito, temos o império de um discurso de domínio que apenas retroalimenta sistematicamente o ciclo de violência. Para que haja um rompimento desse ciclo, é preciso entrar em cena uma preocupação que vá além da simples preservação dos corpos das crianças na escola. É preciso preservar-lhes a possibilidade de ação e transformação, de resposta aos impasses ocasionados pelas recusas cada vez mais insistentes dos modelos tradicionais de escolarização.

\section{CONSIDERACְ̃̃ES FINAIS}

A educação é um processo de formação humana, para além da transmissão de conteúdos formais. Ela ocorre no encontro entre dois desejos, o de ensinar e o de aprender. A transmissão envolve o imprevisto, o inesperado e o ineducável. O crescente desinteresse pela aprendizagem escolar e o aumento da violência nas escolas evidenciam que a escola está em crise. As transformações do laço social consequentes da época atual afetam as relações do aluno com a escola e com os educadores. Estamos diante de um novo contexto que deve ser avaliado em toda a sua complexidade. Os jovens hoje buscam diferentes formas de laço social, marcados pela descentralização, horizontalidade, fragilidade e multiplicidade. A escola não pode manter-se alheia às transformações sociais. Os métodos educacionais não podem ser pautados na centralização do poder e no reforço do controle, que levam ao aumento da violência.

A contribuição psicanalítica nesse processo é por meio da palavra e do incentivo aos projetos que fomentem a sua circulação e que se atentem para a escuta dos sujeitos envolvidos nas situações de conflito, possibilitando a construção de um projeto de trabalho coletivo na instituição escolar. Barros-Brisset nos lembra do desejo 
decidido de Célio Garcia "de que um dia o jovem pudesse largar suas armas e tomar a palavra" (BARROS-BRISSET, 2013, p.6). De fato, ele aponta que, quando alguém fala, o faz a partir de uma posição própria. "Criar condições para o reconhecimento dessa posição subjetiva [...] significa deixar vir sua voz nua e crua, sem garantia de realidade" (GARCIA, 2011b, p.24). Essa perspectiva traz uma inspiração ética profunda, na medida em que a tomada da palavra permite uma enunciação que pode abrir alternativas aos atos de violência. "Eis a forma analítica de dispensar o aprisionamento ao discurso do mestre contemporâneo para dar lugar ao saber fazer de cada um", apresenta Barros-Brisset: "convidando cada um a tomar a palavra para falar mais sobre isso" (BARROS-BRISSET, 2013, p.6).

Como também sugere Lacadée (2000), ao invés de medidas puramente proibitivas, é preciso autorizar os sujeitos a respeitaremse a si mesmos, para que eles possam se reconhecer na sociedade. A escola se ocupa de jovens em formação, que precisam ser amparados nesse momento de suas vidas. Educar é ajudar a construir um sentido para a vida, é despertar, nos jovens, o desejo de viver. Para além da transmissão de conhecimentos universais, a escola deve acolher o novo que cada jovem porta em seu corpo e em sua palavra.

Cabe à escola abrir espaços para a palavra, para a construção de um sentido individual dentro desse espaço coletivo. A criação surge da transgressão, do conflito, presente em todo grupo social. Como adverte Arendt (2000), a violência resulta da severa frustração da faculdade de agir no mundo. É necessário que o sujeito dê o seu consentimento "para participar da teia de relações inter-humanas que constituem toda sociedade" (ARENDT, 2000, p.91). Ao invés de buscar propostas somente de natureza coercitiva, a escola precisa investir em projetos educacionais que garantam a participação ativa de cada um na vida social.

\section{REFERÊNCIAS}

AGAMBEN, G. Homo Sacer: o poder soberano e a vida nua. 2.ed. Trad. Henrique Burigo. Belo Horizonte: Editora UFMG, 2010.

ARANTES, E. M. de M. O anonimato da dor: a quem serve a redução da maioridade penal? Núcleo Interdisciplinar de Pesquisa e Intercâmbio para a Infância e a Adolescência Contemporâneas. Disponível em: <http://www.psicologia.ufrj.br/nipiac/index. php?option $=$ com_content\&view $=$ article\&id $=102>$. Acesso em: 08 maio 2013.

ARENDT, H. Sobre a violência. Trad. André Duarte. Rio de Janeiro: Relume Dumará, 2000. ARREGUY, M. E.; MORENA-TORRES, M.; CAMPOREZ, G. A. Violência simbólica e fracasso escolar: reflexões psicanalíticas na educação. RevistAleph, Rio de Janeiro, ano VI, n.17, p.53-70, jul. 2012. 
ARROYO, M. G. Quando a violência infantojuvenil indaga a pedagogia. Revista Educação e Sociedade, Campinas, v.28, n.100, p.787-807, maio/ago. 2007.

BARROS-BRISSET, F. O. de. "Prega" leve no mundo do furor dominandis. Cien Digital, Belo Horizonte, n.14, p.5-7, abr. 2013. Disponível em: <https://docs.google.com/file/ d/0Bz-7DvJMAGNnNjV2Z1Q4eGEtS2M/preview?pli=1>. Acesso em: 09 maio 2013.

BENJAMIN, W. Documentos de cultura, documentos de barbárie: escritos escolhidos. Seleção e apresentação Willi Bolle; trad. Celeste H. M. Ribeiro de Sousa et al. São Paulo: Cultrix, Editora da Universidade de São Paulo, 1986.

BOURDIEU, P.; PASSERON, J. C. A reprodução: elementos para uma teoria do ensino. Rio de Janeiro: Livraria Francisco Alves Editora, 1975.

CANGUILHEM, G. O normal e o patológico. 6.ed. rev. Rio de Janeiro: Forense Universitária, 2009.

DRAWIN, C. R. O paradoxo antropológico da violência. In: ROSÁRIO, Â. B. do; KYRILLOS NETO, F.; MOREIRA, J. de O. (Orgs.). Faces da violência na contemporaneidade: sociedade e clínica. Barbacena: EdUEMG, 2011. p.12-32.

FLEURI, R. M. Rebeldia e democracia na escola. Revista Brasileira de Educação, Rio de Janeiro, v.13, n.39, p.470-482, set./dez. 2008.

FOUCAULT, M. Vigiar e punir: história da violência nas prisões. Petrópolis: Vozes, 1994.

FOUCAULT, M. História da sexualidade: a vontade de saber. 13.ed. Rio de Janeiro: Graal, 1999.

FRANÇA NETO, O.; RANDOW, R. F. A violência do jovem em conflito com a lei e o laço social. Revista Affectio Societatis, Medellín, Colômbia, v.9, n.16, p.1-13, jun. 2012. Disponível em: <http://aprendeenlinea.udea.edu.co/revistas/index.php/affectiosocietatis/article/ viewFile/12047/10925>. Acesso em: 09 maio 2013.

FREIRE, P. Educação como prática da liberdade. 4.ed. Rio de Janeiro: Paz e Terra, 1974.

FREIRE, P. Pedagogia do oprimido. 3.ed. Rio de Janeiro: Paz e Terra, 1975.

FREUD, S. O futuro de uma ilusão (1927). In: FREUD, S. O futuro de uma ilusão, O mal-estar na civilização e outros trabalhos. Rio de Janeiro: Imago, 1996. v.21, p.11-63. (Edição standard brasileira das obras psicológicas completas de Sigmund Freud).

FREUD, S. O mal-estar na civilização (1930). In: FREUD, S. O futuro de uma ilusão, O mal-estar na civilização e outros trabalbos. Rio de Janeiro: Imago, 1996. v.21, p.65-148. (Edição standard brasileira das obras psicológicas completas de Sigmund Freud).

GARCIA, C. Psicologia e direitos humanos: possibilidades e desafios dessa interlocução. Pesquisas e práticas psicossociais, São João del-Rei, v.5, n.2, p.143-150, ago./dez. 2010. Disponível em: <http://www.ufsj.edu.br/portal2-repositorio/File/revistalapip/volume5_n2/Garcia. pdf>. Acesso em: 09 maio 2013.

GARCIA, C. Responsabilidade sem culpa. In: MATOSO, D. (Org.). Psicologia jurídica: orientação para o real. Belo Horizonte: Ophicina de Arte \& Prosa, 2011a. p.180-198.

GARCIA, C. Estamira, novas formas de existência (por uma clínica da carência). Belo Horizonte: Oficina de Arte \& Prosa, 2011b.

GOLDENBERG, M. (Org.). Violencia en las escuelas. Buenos Aires: Grama, 2011.

GOMES, M. de F. C.; SENA, M. das G. de C. (Orgs.). Dificuldades de aprendizagem na alfabetização. Belo Horizonte: Autêntica, 2006.

LACADÉE, P. Da norma da conversação ao detalhe da conversação. In: LACADÉE, P.; MONNIER, F. (Orgs.). Le pari de la conversation. Paris: Institut du Champs Freudien, CIENCentre interdisciplinaire sur l'Enfant, 1999-2000. p.1-4.

LACAN, J. O Seminário, livro 3: as psicoses (1955-1956). Rio de Janeiro: Jorge Zahar, 1988.

LIMA, N. L.; REZENDE, A. O. O poder normativo nas escolas e seus efeitos sobre os sujeitos. Revista Estilos da Clínica, São Paulo, v.18, n.1, p.34-52, abr. 2013. Disponível em: < http:// pepsic.bvsalud.org/scielo.php?script $=$ sci_arttext\&pid $=$ S1415-71282013000100003\&lng $=p$ t\&nrm=iso >. Acesso em: 25 maio 2013. 
MICHAUD, Y. A violência. São Paulo: Ática, 2001.

MILLER, J.-A. Problemas de pareja, cinco modelos. In: MILLER, J.-A. La pareja y el amor: conversaciones clínicas con Jacques Alain-Miller en Barcelona. Buenos Aires: Paidós, 2003. p.15-20.

UBJETO, J. Violencias escolares. In: GOLDENBERG, M. (Org.). Violencia en las escuelas. Buenos Aires: Grama, 2011. p.23-42.

VASCONCELOS, R. N.; SANTOS, J. S.; SANTIAGO, A. L. B. Abordagem clínicopedagógica do mal-estar das crianças frente às dificuldades escolares. Proceedings online, Formação de profissionais e a criança-sujeito, São Paulo, 2008. Disponível em: <http:// www.proceedings.scielo.br/scielo.php?script=sci_arttext\&pid=MSC0000000032008000100 071\&lng=en\&nrm=abn>. Acesso em: 18 ago. 2013.

SOUZA, M. P. R. de. Problemas de aprendizagem on problemas de escolarização? Associação Brasileira de Psicologia Escolar e Educacional, 2002. Disponível em: <http://wwwabrapee. psc.br/artigo5.htm>. Acesso em: 09 maio 2013.

SPOSITO, M. P. A instituição escolar e a violência. Cadernos de Pesquisa, São Paulo, n.104, p.58-75, jul. 1998. Disponível em: <http://educa.fcc.org.br/scielo.php?script=sci_ arttext\&pid $=$ S0100-15741998000200005\&lng=pt\&nrm=iso $>$. Acesso em: 15 maio 2013. TIZIO, H. (Org.). Reinventar el vinculo educativo: aportaciones de la pedagogia social y del psicoanálisis. Barcelona: Gedisa Editorial, 2005.

ŽIŽEK, S. Violência: seis notas à margem. Lisboa: Relógio D’Água, 2009.

\section{NOTA}

${ }^{1} \mathrm{~A}$ ideia de anomalias sociais remete à discussão empreendida por Canguilhem (2009) sobre a confusão semântica entre anomalia, que teria um sentido mais descritivo, e anormal, que guardaria uma referência a um valor. "Nem toda anomalia é patológica", diz ele, "mas só a existência de anomalias patológicas é que criou uma ciência especial das anomalias que tende normalmente - pelo fato de ser ciência - a banir, da definição da anomalia, qualquer implicação normativa" (CANGUILHEM, 2009, p.52-53). Foucault (1999) mostra precisamente como o biopoder retoma a noção de anomalia para implicar os desvios em relação a uma normatividade social.

Recebido: 18/08/2013

Aprovado: 14/03/2014

Contato:

Universidade Federal de Minas Gerais. Faculdade de Filosofia e Ciências Humanas. Av. Antônio Carlos, 6.627 - Campus Pampulha, Belo Horizonte | MG | Brasil CEP 31.270-901 